\title{
Evaluation of Toxicological Profile of a Polyherbal Formulation
}

\author{
Rafeeq Alam Khan*, Maryam Aslam, Shadab Ahmed \\ Department of Pharmacology, Faculty of Pharmacy and Pharmaceutical Sciences, University of Karachi, Karachi, \\ Pakistan \\ Email: *rkhan1959@gmail.com
}

Received 16 December 2015; accepted 18 January 2016; published 21 January 2016

Copyright (C) 2016 by authors and Scientific Research Publishing Inc.

This work is licensed under the Creative Commons Attribution International License (CC BY). http://creativecommons.org/licenses/by/4.0/

(c) (i) Open Access

\begin{abstract}
In current study toxicological profile of a commonly used herbal formulation was evaluated that is used extensively for gynecological disorders like menorrhagia, metrorrhagia, leucorrhea, irregular menstrual cycle, pre-menstrual syndrome and post-menopausal bleeding. It was also claimed to strengthen endometrium and ovaries. Since this herbal formulation was been used by a large number of population hence there was a need to assess acute and sub-chronic toxicity. Acute oral toxicity $\left(L_{50}\right)$ was observed in albino mice using standard protocols whereas sub-chronic, hematological and histopathological studies were assessed on 24 albino rabbits after giving herbal formulation for 60 days in two doses $(20$ and $60 \mathrm{mg} / \mathrm{kg})$ against control groups. The outcomes of present study showed that the drug is safe up to $5000 \mathrm{mg} / \mathrm{kg}$ following acute oral toxicity test and no mortality was observed during sub chronic toxicity studies. Results of sub-chronic toxicity did not show any significant changes in biochemical, hematological and histopathological parameters. However, some indicators such as urea, creatinine, hemoglobin, and RBC count were altered, but these changes do not correlate with the histopathological results and may be associated to intra individual variations. Despite the safety of the drug in few animals, clinical trials and more investigations on a large number of animals are essentially needed to establish safety and efficacy of the herbal formulation.
\end{abstract}

\section{Keywords}

Acute Oral Toxicity, Sub-Chronic Toxicity, Biochemical Evaluation, Histopathological Examination, Herbal Formulation

\section{Introduction}

Herbal drugs often referred as traditional medicines are used to describe ancient and culture-bound health prac-

*Corresponding author. 
tices existed before the development of research based modern or allopathic medicines [1] [2]. Herbal drugs form a major component of alternative system of healthcare like ayurvedic, homeopathic, naturopathic and Native American Indian medicine. They have made great contributions in the development of modern drugs as around thirty percent of all modern medicines have been derived from higher plants [3] [4]. Among the first active principles to be isolated from plants were morphine, papaverine, atropine and colchicine, which are still used widely for the treatment of various disorders [5] [6]. Herbal medicines are an essential part of traditional health care system in many cultures [7].

Herbs are products of natural origin most often used as self-treatment of diseased states or less than optimal health conditions. Many are without therapeutic effects and some are toxic [8]. Herbal medicines are usually thought to be safe due to its natural origin however several reviews summarize their significant side effects and interactions [9]-[13].

Mostly integrated research focusing the developments of commercially viable and useful herbal medicines, has not been carried out i.e. herbal products is not tested with the scientific rigor required for modern conventional drugs [14]. Various drug interactions are associated with the intake of some herbal medicines that may result in many adverse reactions [15]. Experts suggest that natural does not mean completely safe and high-risk groups like elderly, pediatrics, pregnant and lactating woman, patients with co-morbidities and organ failures should use herbal products with extreme caution; hence toxicological studies are essentially required before their use by general public [8] [16] [17].

The herbal formulation under study consists of Saraca indica, Symplocos racemosa, Valeriana wallichii, Matricaria chamomilla, Vitex agnuscastus and Areca catechu. It is indicated for gynecological disorders like menorrhagia, metrorrhagia, leucorrhea, irregular menstrual cycle, pre-menstrual syndrome and post-menopausal bleeding. It is also claimed to be beneficial for strengthening endometrium and ovaries.

Saraca indica has been used for its astringent and uterine sedative actions. It acts directly on the muscle fibers of uterus and stimulates the endometrium and ovarian tissue. It has oxytocic activity and historically used for the treatment of excessive endometrial bleeding and dysmenorrhea. It is also used for depression in women and for bleeding in Piles [18] [19].

Symplocos racemosa is useful in bowel complaints, Dropsy, liver complaints, fevers, ulcers and scorpionsting. It also resolves inflammation and relaxes uterine tissues, and thus is used for menorrhagia. It is also recommended for skin and eye infections and in cases of hemorrhage [20] [21].

Valeriana wallichii is used for restlessness, sleeping disorders, lack of concentration, stress, headache, epilepsy, menstrual states of agitation, menopause, stomach cramps, colic and uterine spasticity. It is a powerful nerve tonic, stimulant, carminative, antispasmodic, calmative and analeptic [22] [23].

Matricaria chamomilla is a pleasant aromatic plant with a bitter taste. It possesses antispasmodic, expectorant, carminative, anthelmintic, sedative and diuretic properties. It is principally used as a nerve tonic, in false labor pains, dysmenorrhea, metrorrhagia and cramps in the leg [24].

Vitex agnuscastus is a deciduous tree indigenous to the Mediterranean region as far as western Asia. In folk medicine, it has been used to treat infertility, amenorrhea and hormonal imbalance in both sexes, and also to prevent pre-menstrual mastodynia [25] [26].

Areca catechu has intoxicant, stimulant, astringent, vermifuge, taenifuge, nerve tonic and emmenagogue properties. It is used in the treatment of cholera, colitis, diarrhea, dysentery, fatigue, fever, gastrosis, gonorrhea, leucorrhea, hematuria, herpes, hysteria, malaria, small pox, and tapeworm [27] [28].

Since no legal guidelines exist for regulating the manufacturing, packaging, marketing and use of herbal drugs in Pakistan, these drugs are freely available in the market to be used through self-guidance or untrained advise. Hence pharmacological and toxicological evaluation of such drugs is very important, where large populations are exposed to such preparations without prescription from a licensed or trained medical practitioner.

\section{Material and Method}

\subsection{Selection of Animals}

Two different animal species mice and rabbits were selected for present investigation acute toxicity studies were done on mice and sub-chronic studies were performed on rabbits. 


\subsection{Acute Toxicity Testing ( $\left.L D_{50}\right)$}

Acute oral toxicity $\left(\mathrm{LD}_{50}\right)$ was performed by the method of Lorke [29]. Albino mice of either sex; weighing 20 $25 \mathrm{gm}$, were maintained under persistent environmental conditions $25^{\circ} \mathrm{C} \pm 2^{\circ} \mathrm{C}$ and were provided standard diet and water ad libitum. Three groups of mice each comprising of 3 animals was administered with 10, 100 and $1000 \mathrm{mg} / \mathrm{kg}$ of herbal formulation by mouth and examined for mortality within 24 hours. Following the results of mortality in each group, another set of 3 groups of mice were administered higher doses of the test drug, to achieve the least and most toxic value and $\mathrm{LD}_{50}$ was calculated by geometric mean of the values.

\subsection{Sub-Chronic Toxicity}

This test was performed on 24 healthy white rabbits of either sex from 1200 to 1800 grams. All animals were equally separated into three groups, one group regarded as control and other two received 20 and $60 \mathrm{mg} / \mathrm{kg}$ doses of herbal formulation for consecutive 60 days through oral intubation tube. Doses were prepared in DMSO however control group received DMSO orally equal to the volume of individual doses according to their body weight. Before administration of drug, physical health of these animals was observed during the conditioning period under the laboratory environment for a week explicitly seeing loss of hair, diarrhea, edema, ulceration and lack of activity.

\subsection{Sample Collection}

Blood sample of around $6 \mathrm{ml}$ were collected from these animals by cardiac puncture at the completion of dosing on $61^{\text {st }}$ day to determine various biochemical and hematological parameters.

\subsection{Assessment of Toxicities}

\subsubsection{Physical Examination}

Gross toxicities were perceived every one-week after giving herbal formulation for 60 days explicitly noticing skin ulceration, average weight variation, loss of hair, loss of appetite, loss of activity, hematuria, vomiting, diarrhea, edema, lacrimation, salivation, muscle tone, tremor and aggressive behavior. Autopsy was performed after random selection, at the completion of dosage and sample collection for biochemical tests.

\subsubsection{Biochemical Evaluation}

Blood samples were collected from fasted animals prior to necropsy. Approximately $7 \mathrm{ml}$ of blood samples were collected by cardio puncture. Serum were immediately separated by centrifugation for $10 \mathrm{~min}$ at $4000 \mathrm{rpm}$ and was examined for the following parameters within 3 hours of sample collection on Humalyzer 3000 (GmBH Germany) at $37^{\circ} \mathrm{C}$ utilizing reagents supplied by Human Gmbh Germany.

1) Cardiac parameters: CK-NAC, LDH, AST.

2) Renal parameters: Total protein, urea, creatinine, uric acid.

3) Hepatic parameters: Alkaline phosphatase, ALT, $\gamma$-GT, total and direct bilirubin.

4) Lipid profile: cholesterol and triglycerides.

5) Blood glucose level.

6) Calcium and phosphorus.

\subsubsection{Hematological Evaluation}

Blood samples were collected under $10 \%$ EDTA at $7.2 \mathrm{pH}$ and hematological parameters i.e. RBC, WBC, PLT, Hematocrit, \& hemoglobin were explored using Humacount hematology analyzer GmbH 17400, a fully automated cell counter with a built-in veterinary software module.

\subsubsection{Microscopic Examination}

Representative blocks from different areas of heart, liver and kidney were cut from each sample after separating all fat from respective organs. The blocks were processed through Gilford $101 \mathrm{~s}$ automatic tissue processor.

Tissue slices of $3-4$ micron were taken from the wax blocks by rotary microtome. The tissue slices were mounted on slides and dehydrated softly by pressing with filter paper. The mounted slides were placed primarily for drying on a hot plate $\left(45^{\circ} \mathrm{C}\right)$ for 90 minutes and then left in an incubator at $37^{\circ} \mathrm{C}$ overnight to dry before microscopic examination. 


\subsection{Statistical Analysis}

All the values for biochemical tests were stated as the mean and standard error to the mean (S.E.M.) and were analyzed by using one way unstacked ANOVA and p values were observed [30]. Results were considered significant if $\mathrm{p}$ value was less than 0.05 and highly significant if $\mathrm{p}$ value was less than 0.005 .

\section{Results}

\subsection{Physical Examination}

Apparent physical health of the animals was observed in various groups on different doses of herbal formulation during the entire period of experiment.

Skin ulceration, average weight variation, loss of hair, loss of appetite, loss of activity, hematuria, vomiting, diarrhea, edema, lacrimation, salivation, respiratory rate, muscle tone, exophthalmia, tremor, and aggressive behavior. Animals of no group exhibited gross toxicities at any time during the entire period of experiment and none of the animals expired.

\subsection{Biochemical Evaluation}

Table 1 reveals the comparison of biochemical markers e.g. CK-NAC, LDH, AST, Total protein, urea, creatinine, uric acid, ALP, ALT, $\gamma$-GT, Total and Direct Bilirubin, cholesterol, triglycerides, calcium, phosphorus and glucose following 20 and $60 \mathrm{mg} / \mathrm{kg}$ dose administration of herbal formulation for 60 days.

Generally results did not reveal any significant toxicity. Herbal formulation had elevated serum urea highly significantly at $20 \mathrm{mg} / \mathrm{kg}$ however at $60 \mathrm{mg} / \mathrm{kg}$ the increase was significant, as compared to control. Serum creatinine was also reduced significantly at $60 \mathrm{mg} / \mathrm{kg}$ as compared to control. Rest of the biochemical parameter appears to be in normal ranges with respect to control group animals.

Table 1. Effect of herbal formulation after 60 days on biochemical markers.

\begin{tabular}{|c|c|c|c|}
\hline \multirow{3}{*}{ Parameters } & \multicolumn{3}{|c|}{ Animal groups } \\
\hline & \multirow{2}{*}{ Control } & \multicolumn{2}{|c|}{ Herbal formulation } \\
\hline & & $20 \mathrm{mg} / \mathrm{kg}$ & $60 \mathrm{mg} / \mathrm{kg}$ \\
\hline CK-NAC (U/I) & $470 \pm 58$ & $479 \pm 102$ & $494 \pm 48$ \\
\hline LDH (U/l) & $236 \pm 33$ & $216 \pm 33$ & $252 \pm 33$ \\
\hline AST (U/l) & $95 \pm 21$ & $66.7 \pm 16.7$ & $59 \pm 7.4$ \\
\hline Tot. Protein (gm/dl) & $7.94 \pm 0.65$ & $6.74 \pm 0.68$ & $8.1 \pm 1.86$ \\
\hline Urea (mg/dl) & $20.35 \pm 3.18$ & $59.69 \pm 4.6^{* *}$ & $33.3 \pm 1.93^{*}$ \\
\hline Creatinine (mg/dl) & $1.67 \pm 0.132$ & $1.95 \pm 0.13$ & $1.21 \pm 0.11^{*}$ \\
\hline Uric Acid (mg/dl) & $1.34 \pm 0.295$ & $0.76 \pm 0.24$ & $1.08 \pm 0.18$ \\
\hline $\operatorname{ALP}(\mathrm{U} / \mathrm{I})$ & $86.4 \pm 16.85$ & $86.5 \pm 21.9$ & $75.14 \pm 17.67$ \\
\hline $\operatorname{ALT}(\mathrm{U} / \mathrm{l})$ & $75.3 \pm 8.5$ & $86.6 \pm 19.6$ & $57.14 \pm 5.89$ \\
\hline$\gamma \mathrm{GT}(\mathrm{U} / \mathrm{l})$ & $6.43 \pm 0.428$ & $7.7 \pm 0.92$ & $6.57 \pm 0.84$ \\
\hline Tot. Bilirubin (mg/dl) & $0.34 \pm 0.02$ & $0.3 \pm 0.08$ & $0.4 \pm 0.07$ \\
\hline Dir. Bilirubin (mg/dl) & $0.08 \pm 0.02$ & $0.09 \pm 0.01$ & $0.09 \pm 0.01$ \\
\hline Cholesterol (mg/dl) & $14.40 \pm 2.6$ & $15.7 \pm 3.53$ & $9.7 \pm 2.86$ \\
\hline Triglycerides (mg/dl) & $59.43 \pm 13.89$ & $38.43 \pm 8.9$ & $52.6 \pm 17$ \\
\hline Calcium (mg/dl) & $7.5 \pm 1.5$ & $8.68 \pm 1.39$ & $8.86 \pm 0.99$ \\
\hline Phosphorus (mg/dl) & $6.56 \pm 0.51$ & $6.82 \pm 0.88$ & $6.22 \pm 0.43$ \\
\hline Glucose (mg/dl) & $178 \pm 27.65$ & $173.9 \pm 29.78$ & $133.3 \pm 2.18$ \\
\hline
\end{tabular}

$\mathrm{n}=8$. Average values \pm S.E.M. ${ }^{*} \mathrm{p}<0.05$ significant as compared to control. ${ }^{* *} \mathrm{p}<0.005$ highly significant as compared to control. 


\subsection{Hematological Evaluation}

Table 2 reveals the comparison of Hemoglobin, Hematocrit, RBC, WBC, and Platelet following 20 and 60 $\mathrm{mg} / \mathrm{kg}$ dose of herbal formulation for 60 days. There was highly significant decrease in hemoglobin hematocrit and significant decrease in RBC count at $60 \mathrm{mg} / \mathrm{kg}$ dose of herbal formulation, in comparison to control group, while there was no significant change in WBCs and platelet count, in comparison to control group animals.

\subsection{Microscopic Examination}

Gross examination of various vital organs such as heart, liver and kidney showed no significant macroscopic changes in any group. However, on microscopic examination, one animal at $60 \mathrm{mg} / \mathrm{kg}$ revealed congestion and mild focal interstitial inflammation in renal tissue (Figure 1). Similarly one animal at $60 \mathrm{mg} / \mathrm{kg}$ also showed congestion with mild portal inflammation in hepatic tissue (Figure 2) but rest of the animals did not revealed any cellular changes (Figure 3 \& Figure 4).

\section{Discussion}

Herbal medicine is the oldest form of healthcare and had been used by all cultures throughout history. The WHO has assessed that $80 \%$ of the world's population stays to use traditional therapies, a main part of which are obtained from plants, as their primary health care tools [4] [31].

Table 2. Effects of herbal formulation after 60 days on hematological parameters.

\begin{tabular}{cccc}
\hline & & \multicolumn{2}{c}{ Animal groups } \\
\cline { 3 - 4 } Parameters & Control & \multicolumn{2}{c}{ Herbal formulation } \\
\cline { 2 - 3 } & $10.6 \pm 0.25$ & $9.5 \pm 0.77$ & $60 \mathrm{mg} / \mathrm{kg}$ \\
\hline Hemoglobin $(\mathrm{gm} / \mathrm{dl})$ & $33.93 \pm 0.73$ & $30.28 \pm 2.22$ & $9 \pm 0.382^{* *}$ \\
Hematocrit $(\%)$ & $5.49 \pm 0.21$ & $5.03 \pm 0.43$ & $29.69 \pm 0.85^{* *}$ \\
RBC $\times 10^{6} / \mu \mathrm{l}$ & $5.44 \pm 0.51$ & $3.98 \pm 0.45$ & $4.87 \pm 0.13^{*}$ \\
WBC $\times 10^{3} / \mu \mathrm{l}$ & $306 \pm 49$ & $324 \pm 44.4$ & $4.25 \pm 0.32$ \\
Platelet $\times 10^{3} / \mu \mathrm{l}$ & & $433 \pm 62$ \\
\hline
\end{tabular}

$\mathrm{n}=8$. Average values \pm S.E.M. ${ }^{*} \mathrm{p}<0.05$ significant as compared to control. ${ }^{* *} \mathrm{p}<0.005$ highly significant as compared to control.

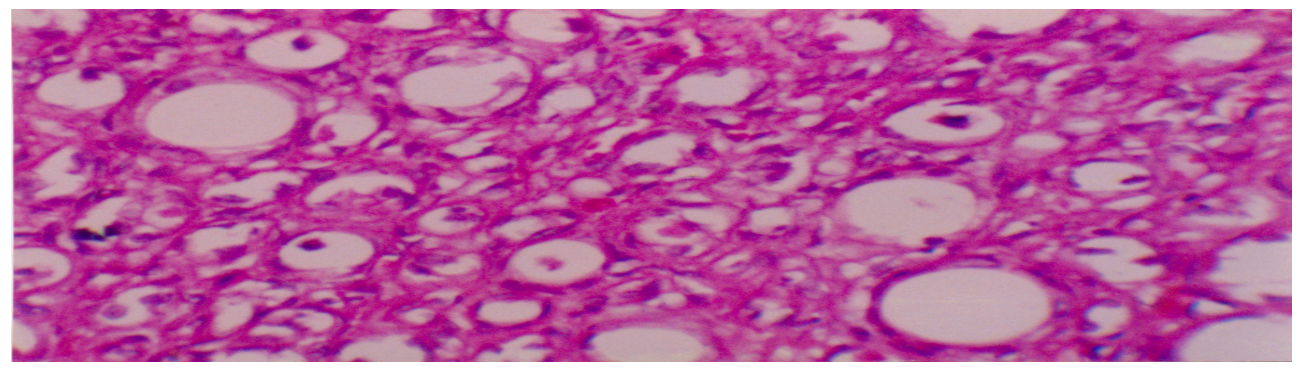

Figure 1. Renal tissue showing congestion and mild focal interstitial inflammation.

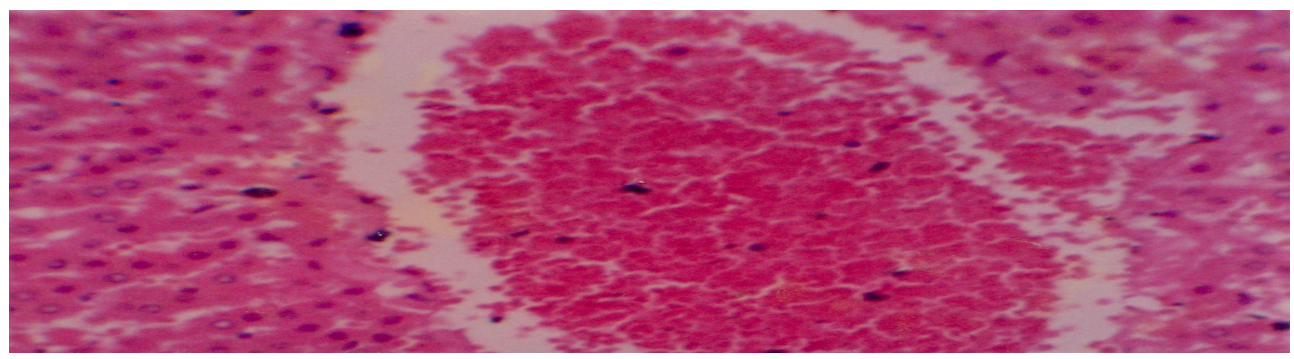

Figure 2. Hepatic tissue showing congestion and mild portal inflammation. 


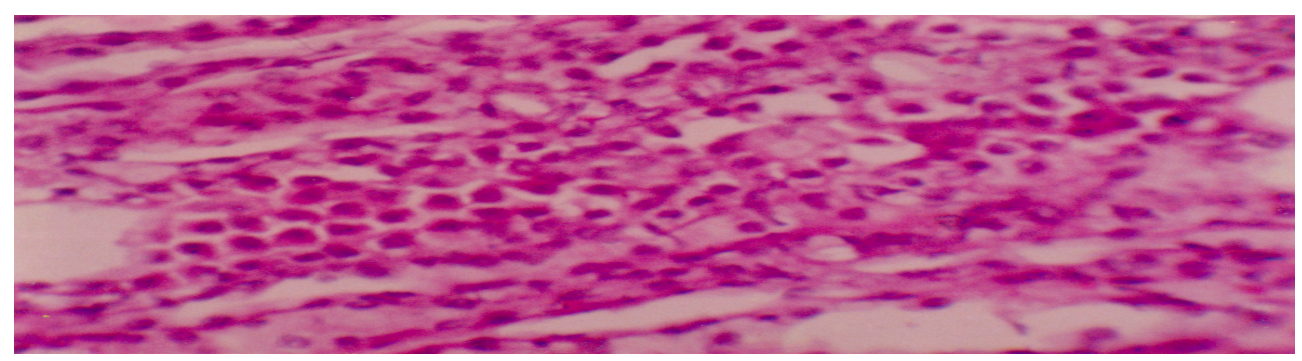

Figure 3. Hepatic tissue showing no microscopic changes.

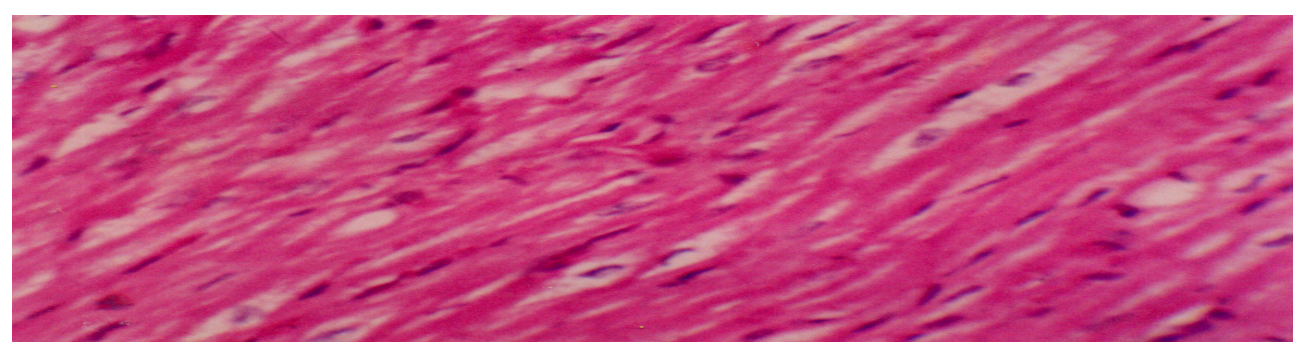

Figure 4. Cardiac tissue showing no microscopic changes.

Herbal medicines are usually regarded as safe, but case reports indicate that serious side effects and pertinent interactions with other drugs can arise altering physiology and these changes can be reflected in abnormal test results [32] [33]. Hence plants should be evaluated by modern scientific methods in order to demonstrate their usefulness and to avoid the use of useless and toxic herbs. Thus, herbal formulation was evaluated for its safety against gross toxicities and toxic effects on biochemical, hematological and histopathological parameters in rabbits.

The overall physiology of rabbits is comparable to humans, thus rabbits have been used as a model for human diseases. Rabbits are large enough to provide suitable amounts of tissue for experimental work without pooling of samples but are small enough to be economical for most studies.

Moreover rabbits were selected since biochemical and histopathological changes made are comparatively similar as observed in humans [34]. Secondly, sufficient amount of blood samples can be obtained at different stages of experiment and thirdly, rabbits are not only easily available but are also easy to handle.

The result of acute toxicity $\left(\mathrm{LD}_{50}\right)$ after oral administration reveals that herbal formulation has $\mathrm{LD}_{50}$ greater than $5000 \mathrm{mg} / \mathrm{kg}$. Moreover, there was no death reported at any dose following administration of herbal formulation for 60 days. These findings suggest that this preparation possesses wide therapeutic range and is relatively safe.

In present study, comparison of gross toxicities e.g. skin ulceration, weight variation, loss of hair, loss of activity, hematuria, loss of interest in food, vomiting, diarrhea, edema, salivation, and aggressive behavior etc., were seen after the administration of herbal formulation during the entire period of experiment. The results showed no significant toxicities, however, average weight loss was observed during the course of experimentation in animals of all three groups.

Study of the renal profile such as total protein, urea, creatinine, and uric acid levels give useful information about the drug-induced renal toxicities. Animals which received herbal formulation in 20 and $60 \mathrm{mg} / \mathrm{kg}$ doses did not show any significant changes in total protein and uric acid levels. However, animals at $20 \mathrm{mg} / \mathrm{kg}$ dose showed highly significant increase in urea, while, animals at $60 \mathrm{mg} / \mathrm{kg}$ showed less significant increase in urea and significant decrease in creatinine. The decrease in urea was not consistent with the dose and might be due to increased protein metabolism also indicated by weight loss in all animal groups.

Liver damage tempted by drugs may consist of hepatocellular necrosis, cholestasis, or a mixture of biochemical and histopathological patterns [35]. The estimation of AST and ALP is suitable in the early diagnosis of viral or toxic hepatitis and thus patients exposed to hepatotoxic drugs [36]. Hence animals were tested for ALP, AST, $\gamma$-GT and Bilirubin levels to check for hepatic toxicity. There were no significant changes ALP, AST, $\gamma$-GT and Bilirubin (Total and Direct) in animals of either group received herbal formulation.

Animals received 20 and $60 \mathrm{mg} / \mathrm{kg}$ doses of herbal formulation did not show any significant changes in Cardiac enzymes such as LDH, CK and GOT. Moreover, microscopic examination of cardiac tissue also did not re- 
veal any Cardiac damage.

Animals received 20 and $60 \mathrm{mg} / \mathrm{kg}$ doses of herbal formulation showed no significant changes in lipid profile (triglycerides and cholesterol) and other biochemical parameters (glucose, calcium and phosphorus).

Study of the hematological parameters like hemoglobin concentration, hematocrit, RBC, WBC, and platelet count gives valuable information about the drug-induced hematological toxicities. Animals received $60 \mathrm{mg} / \mathrm{kg}$ doses of herbal formulation showed highly significant decrease in hemoglobin and hematocrit, and significant decrease in RBC count.

The herbal formulation did not revealed any macroscopic changes at $20 \mathrm{mg}$ as well as $60 \mathrm{mg} / \mathrm{kg}$ doses, similarly microscopic examination in animals received 20 and $60 \mathrm{mg} / \mathrm{kg}$ herbal formulation did not reveal any remarkable changes in heart. However, there was mild focal interstitial inflammation in kidney at $60 \mathrm{mg} / \mathrm{kg}$, which might be due to intra individual variation, since biochemical changes do not confirm any damage in these tissues. Similarly there was mild portal inflammation in hepatic tissue of animals at $20 \mathrm{mg} / \mathrm{kg}$ which might be due to any circulating antigen, since biochemical alterations did not correlate microscopic changes and are thus insignificant.

\section{Conclusion}

Investigation on acute, sub-chronic, biochemical, hematological and histopathological parameters did not reveal any significant toxicity; therefore it may indeed be concluded as safe formulation; however despite safety of the drug in animals, trial in humans is the only valid way of establishing safety and efficacy of any drug prior to use in humans.

\section{Acknowledgements}

Authors are grateful to Herbion Pakistan Limited for providing herbal formulation and financial support to complete this piece of work.

\section{References}

[1] Farnsworth, N.R. (1988) Screening of Plants for New Medicines. In: Wilson, E.O., Ed., Chapter 9 in Biodiversity, National Academy Press, Washington DC.

[2] Gurib-Fakim, A. (2006) Medicinal Plants: Traditions of Yesterday and Drugs of Tomorrow. Molecular Aspects of Medicine, 27, 1-93. http://dx.doi.org/10.1016/j.mam.2005.07.008

[3] Burns, M.M. (2000) Alternative Medicine: Herbal Preparation. Clinical Pediatric Emergency Medicine, 1, $186-190$. http://dx.doi.org/10.1016/S1522-8401(00)90026-0

[4] Khan, R.A., Arif, M., Sherwani, B. and Ahmed, M. (2013) Acute and Sub Chronic Toxicity of Mucuna pruriens, Cinnamomum zeylanicum, Myristica fragrans and Their Effects on Hematological Parameters. Australian Journal of Basic and Applied Sciences, 7, 641-647.

[5] Drews, J. (2000) Drug Discovery: A Historical Perspective. Science, 287, 1960-1964. http://dx.doi.org/10.1126/science.287.5460.1960

[6] Newman, D.J., Cragg, G.M. and Snada, K.M. (2000) The Influence of Natural Products upon Drug Discovery. Natural products Reports, 17, 215-234. http://dx.doi.org/10.1039/a902202c

[7] Vickers, A. and Zollman, C. (1999) ABC of Complementary Medicine: Herbal Medicine. British Medical Journal, 319, 1050-1053. http://dx.doi.org/10.1136/bmj.319.7216.1050

[8] Tyler, V.E., Brady, L.R. and Robbers, J.E. (1988) Pharmacognosy. 9th Edition, Lea \& Febiger, Philadelphia.

[9] De Smet, P.A.G.M. (1997) The Role of Plant-Derived Drugs and Herbal Medicines in Healthcare. Drugs, 54, 801-840. http://dx.doi.org/10.2165/00003495-199754060-00003

[10] Miller, L.G. (1998) Hepatotoxic Herbs. Archives of Internal Medicine, 158, 2200-2210. http://dx.doi.org/10.1001/archinte.158.20.2200

[11] Ernst, E. (2000) Possible Interactions between Synthetic and Herbal Medicinal Products. Part 1: A Systematic Review of the Indirect Evidence. Perfusion, 13, 4-15.

[12] Ernst, E. (2000) Possible Interactions between Synthetic and Herbal Medicinal Products. Part 2: A Systematic Review of the Direct Evidence. Perfusion, 13, 60-70.

[13] Skalli, S., Zaid, A. and Soulaymani, R. (2007) Drug Interactions with Herbal Medicines. Therapeutic Drug Monitoring, 


\section{9, 1-7. http://dx.doi.org/10.1097/FTD.0b013e31815c17f6}

[14] Subramoniam, A. (2001) The Problems and Prospects of Plant Drug Research in India: Pharmacological Evaluation of Ecotypes in Herbal Drug Development. Indian Journal of Pharmacology, 33, 145-146.

[15] Kistorp, T.K. and Laursen, S.B. (2002) Herbal Medicines-Evidence and Drug Interactions in Clinical Practice. Ugeskr Laeger, 164, 4161-4165.

[16] World Health Organization (1991) Guidelines for the Assessment of Herbal Medicines. Program on Traditional Medicines, Geneva, 1-4.

[17] World Health Organization (2005) WHO Global Atlas of Traditional, Complementary and Alternative Medicine. World Health Organization, Geneva, 1-2.

[18] Venugopal, S. (1998) Effect of Eve Care in Oligomenorrhoea. Antiseptic, 95, 329-330.

[19] Pradhan, P., Joseph, L., Gupta, V., Chulet, R., Arya, H., Verma, R. and Bajpai, A. (2009) Saraca Asoca (Ashoka): A Review. Journal of Chemical and Pharmaceutical Research, 1, 62-71.

[20] Bhutani, K.K., Jadhav, A.N. and Kalia, V. (2004) Effect of Symplocos racemosa Roxb. on Gonadotropin Release in Immature Female Rats and Ovarian Histology. Journal of Ethnopharmacology, 94, 197-200. http://dx.doi.org/10.1016/j.jep.2004.04.022

[21] Jadhav, A.N. and Bhutani, K.K. (2005) Ayurveda and Gynecological Disorders. Journal of Ethnopharmacology, 97, 151-159. http://dx.doi.org/10.1016/j.jep.2004.10.020

[22] Gilani, A.H., Khan, A.U., Jabeen, Q., Subhan, F. and Ghafar, R. (2005) Antispasmodic and Blood Pressure Lowering Effects of Valeriana wallichii Are Mediated through K+ Channel Activation. Journal of Ethnopharmacology, 100, 347-352. http://dx.doi.org/10.1016/j.jep.2005.05.010

[23] Sahu, S., Ray, K., Yogendra, K.M.S., Gupta, S., Kauser, H., Kumar, S., Mishra, K. and Panjwani, U. (2012) Valeriana wallichii Root Extract Improves Sleep Quality and Modulates Brain Monoamine Level in Rats. Phytomedicine, 19, 924-929. http://dx.doi.org/10.1016/j.phymed.2012.05.005

[24] Avallone, R., Zanoli, P., Corsi, L., Cannazza, G. and Baraldi, M. (1996) Benzodiazepine-Like Compounds and GABA in Flower Head of Matricaria chamomilla. Phytotherapy Research, 10, s177-s179.

[25] Christoffel, V., Spengler, B., Jarry, H. and Wuttke, W. (1999) Prolactin Inhibiting Dopaminergic Activity of Diterpenes from Vitex Agnus Castus. In: Loew, D., Blume, H. and Dingermann, T., Eds., Phytopharmaka V, Springer-Verlag, Berlin Heidelberg, 209-214. http://dx.doi.org/10.1007/978-3-642-58709-2_25

[26] van Diana, D., Burger, H.G., Teede, H. and Bone, K. (2012) Vitex Agnus-Castus Extracts for Female Reproductive Disorders: A Systematic Review of Clinical Trials. Planta Medica, 79, 562-575.

[27] Gilani, A.H., Ghayur, M.N., Saify, Z.S., Ahmed, S.P., Choudhary, M.I. and Khalid, A. (2004) Presence of Cholinomimetic and Acetylcholinesterase Inhibitory Constituents in Betel Nut. Life Science, 75, 2377-2389. http://dx.doi.org/10.1016/j.lfs.2004.03.035

[28] Peng, W., Liu, Y.-J., Wu, N., Sun, T., He, X.-Y. and Gao, Y.-X. (2015) Areca catechu L. (Arecaceae): A Review of Its Traditional Uses, Botany, Phytochemistry, Pharmacology and Toxicology. Journal of Ethnopharmacology, 164, 340356. http://dx.doi.org/10.1016/j.jep.2015.02.010

[29] Lorke, D. (1983) A New Approach to Practical Acute Toxicity Testing. Archives of Toxicology, 54, 275-287. http://dx.doi.org/10.1007/BF01234480

[30] Larson, D.A. (1992) Analysis of Variance with Just Summary Statistics as Input. The American Statistician, 46, 151-152.

[31] Akerele, O. (1993) Summary of WHO Guidelines for the Assessment of Herbal Medicines. Herbal Gram, 28, 13-19.

[32] Barnes, J., Anderson, L.A. and Phillipson, J.D. (2007) Herbal Medicine. 3rd Edition, Pharmaceutical Press, London, 123.

[33] Tsai, H.H., Lin, H.W., Simon, A.P. and Mahady, G.B. (2012) Evaluation of Documented Drug Interactions and Contraindications Associated with Herbs and Dietary Supplements: A Systematic Literature Review. International Journal of Clinical Practice, 66, 1056-1078. http://dx.doi.org/10.1111/j.1742-1241.2012.03008.x

[34] Chojnowska, I., Kucharczyk, K., Myszkowski, L., Radzikowski, A. and Szymańska, K. (1979) Blood Serum Proteins in Experimental Chronic Liver Injury in Rabbit. Patologia Polska, 30, 71-88.

[35] Bonadonna, G. (1988) Chemotherapy Induced Complications. In: Bonadonna, G. and Robustelli-Della-Cuna, G., Eds., Handbook of Medical Oncology, 3rd Edition, Masson, Milano, Parigi, Barecellona and Mexico, 963-975.

[36] Zimmerman, H.J. (1984) Function and Integrity of the Liver. In: Henry, J.B., Ed., Clinical Diagnosis and Management by Laboratory Methods, 17th Edition, W. B. Saunders, Philadelphia, 217-250. 